\title{
XIMІЧНІ ТЕХНОЛОГIÏ
}

УДК $666+553.493 .34$

DOI: $10.20535 / 1810-0546.2016 .2 .60863$

\author{
С.В. Пилипко, Л.М. Спасьонова, М.М. Племянніков \\ Національний технічний університет України “КПІ”, Київ, Україна

\section{СИНТЕЗ ЛЮМІНЕСЦЕНТНИХ МАТЕРІАЛІВ НА ОСНОВІ РІДКІСНОЗЕМЕЛЬНИХ ОКСОФТОРИДІВ}

\begin{abstract}
Background. Development of new materials for the systems of reflection and registration of visual signals that can work in the infrared range remains an ongoing. Industry of optics ran into a problem, when the known systems based on silicate glass do not provide the necessary width of zone of transparency, and materials based on fluoride of metals have subzero chemical firmness.

Objective. The aim of the work is development of the methodology towards the synthesis and research of properties of fluoride glasses and oxyfluorides of rare-earth elements (REE) and yttrium.

Methods. To achieve the goal approach is applied in relation to a synthesis and research with the use of thermal, $\mathrm{X}$-rayed, luminescent and other methods. As initial substances commercial connections $\mathrm{ZrF}_{4} ; \mathrm{LaF}_{3} ; \mathrm{AlF}_{3} ; \mathrm{GaF}_{3} ; \mathrm{BaF}_{2}$; $\mathrm{YF}_{3} ; \mathrm{Y}_{2} \mathrm{O}_{3} ; \mathrm{EuF}_{3} ; \mathrm{Eu}_{2} \mathrm{O}_{3} ; \mathrm{GdF}_{3} ; \mathrm{Gd}_{2} \mathrm{O}_{3} ; \mathrm{TbF}_{3} ; \mathrm{Tb}_{2} \mathrm{O}_{3}$ were used.

Results. The possibility to create luminescent materials based on fluoride glasses of 95\% ZLAG + 5\% ZBLA and oxyfluorides of REE has been studied. For synthesis of these materials europium and terbium compounds have been used as luminophores emitting in visible spectrum.

Conclusions. According to the experimental data, it can be concluded that synthesized fluoride glasses can be used as perspective materials for optic amplifiers and lasers, where besides physical properties, one of the most important requirements is a possibility to take a necessary form of final product. The oxyfluorides having good photoluminescent yield and resistivity to aggressive milieu can be perspective materials for luminescent dispositifs of common use.
\end{abstract}

Keywords: luminescent materials; fluoride glass; oxyfluorides; rare-earth elements.

\section{Вступ}

Галузь оптики зіткнулася 3 проблемою, коли відомі системи на основі силікатного скла не забезпечують необхідної ширини зони прозорості, а матеріали на основі фторидів металів мають низьку хімічну стійкість $[1,2]$. Актуальним $є$ створення матеріалів, здатних працювати в діапазоні інфрачервоного випромінювання. Прогнозовано перспективними $€$ матриці на основі стекол фторидів металів і оксофторидів рідкісноземельних елементів (РЗЕ) та ітрію [3].

Запити квантової, побутової та промислової електроніки, орієнтовані на люмінесцентні приймачі та перетворювачі для роботи у діапазоні рентгенівського, ультрафіолетового або інфрачервоного випромінювання, стимулювали роботи із синтезу та дослідження нових люмінесцентних матеріалів. Число ж ефективних люмінесцентних матриць обмежене хімічною стійкістю, технологічними труднощами синтезу чи надмірною токсичністю вихідних реагентів $\mathrm{i}$ кінцевих продуктів [4].

\section{Постановка задачі}

Метою роботи є розроблення методології, спрямованої на синтез та дослідження властивостей фторидних стекол і оксофторидів РЗЕ та ітрію.

\section{Матеріали і методи}

Об’єктом досліджень були вибрані матриці люмінесцентних матеріалів на основі оксофторидів РЗЕ та ітрію і фторидних стекол.

Для досягнення мети застосовано комплексний підхід до синтезу та досліджень із використанням термічних, рентгенівських, люмінесцентних та інших методів. Як вихідні речовини використовувалися комерційні сполуки $\mathrm{ZrF}_{4}$; $\mathrm{LaF}_{3} ; \mathrm{AlF}_{3} ; \mathrm{GaF}_{3} ; \mathrm{BaF}_{2} ; \mathrm{YF}_{3} ; \mathrm{Y}_{2} \mathrm{O}_{3} ; \mathrm{EuF}_{3} ; \mathrm{Eu}_{2} \mathrm{O}_{3}$; $\mathrm{GdF}_{3} ; \mathrm{Gd}_{2} \mathrm{O}_{3} ; \mathrm{TbF}_{3} ; \mathrm{Tb}_{2} \mathrm{O}_{3} 3$ характеристичним вмістом $\approx 99,9 \%$.

\section{Результати і їх обговорення}

Отримання специфічних люмінесцентних матеріалів передбачає легування вибраної матриці відповідними люмінофорами: фторидами та оксидами РЗЕ, а саме європієм і тербієм, які мають досить інтенсивне випромінювання у видимій області спектра.

При виборі люмінофору необхідно враховувати, що через різну заповненість $4 f$-електронної оболонки кожен іон рідкісноземельних металів має власний спектр випромінювання, який може залежати від будови матриці і визначається екрануванням електронів $4 f$-рівня. Розщеплення енергетичних рівнів під впливом 
кристалічної гратки є малим й істотно не змінює діапазон при збудженні в інфрачервоному або ультрафіолетовому діапазонах спектра.

Обмеженням при використанні існуючих оптичних систем на основі силікатного скла $є$ мала ширина вікна пропускання сигналу, яка лімітується фононною вібрацією структури матриці в зоні інфрачервоного випромінювання (при $\lambda>1,6$ мкм). Перспективним матеріалом для заміни стандартних систем є група фторидних стекол з широким вікном прозорості в діапазоні довжин хвиль від 0,3 до 8 мкм, 3 низькою температурою їх склування (300$\left.400{ }^{\circ} \mathrm{C}\right)$ та близьким до силікатного скла показником заломлення.

У роботі проведені дослідження матриці ZLAG, що являє собою продукт синтезу фторидів металів: $\mathrm{ZrF}_{4}-\mathrm{LaF}_{3}-\mathrm{AlF}_{3}-\mathrm{GaF}_{3}$. Оскільки матриця ZLAG схильна до неконтрольованої кристалізаціі, для полегшення синтезу до вихідної суміші додавалася домішка матриці ZBLA у кількості 5 мол. \%: $\mathrm{ZrF}_{4}-\mathrm{BaF}_{2}-\mathrm{LaF}_{3}-\mathrm{AlF}_{3}$.

Залучені до синтезу скла компоненти можна розділити на три групи залежно від ролі у процесі формування матриці:

1) $\mathrm{ZrF}_{4}$ - склоутворювач, виконує роль скелета матриці; без нього неможливе утворення твердої аморфної структури;

2) $\mathrm{LaF}_{3}, \mathrm{AlF}_{3}, \mathrm{GaF}_{3}$ - проміжні речовини, які не здатні утворювати аморфний скелет, але в обмежених кількостях здатні заміщувати склоутворювач, тим самим змінюючи характеристики скла;

3) $\mathrm{BaF}_{2}$ - модифікатор, який, розриваючи місткові зв'язки $\mathrm{Me}-\mathrm{F}$ ( $\mathrm{Me}-\mathrm{Zr}$, La, $\mathrm{Al}, \mathrm{Ba})$, змінює властивості скла.

Незважаючи на високу електронегативність іонів $\mathrm{F}^{-}$та силу зв'язку $\mathrm{Me}-\mathrm{F}$, цей тип стекол $€$ хімічно малостійким, що пов'язано 3 наявністю в структурі фторидного скла трьох типів зв'язків $\mathrm{Me}-\mathrm{F}$ : іони $\mathrm{F}^{-}$зв'язуються 3 іонами металів через подвійний місток, одинарний місток та через одиничний зв'язок. Це зумовлює зниження оптичних властивостей скла активним заміщенням іонів фтору на гідроксогрупу при контакті з повітрям та призводить до утворення центрів кристалізації 3 подальшим руйнуванням аморфної структури.

Для отримання фторидного скла вибрано метод взаємодії вихідних компонентів у формі пудр під час їх розплавлення у платиновому тиглі. Через високу летючість фторидів тигель необхідно накривати платиновою кришкою.
Відповідно, умови синтезу мають забезпечувати мінімальну витримку за високих температур для збереження стехіометрії. Під час процесу плавки побічні продукти синтезу відсутні. Склад матриць стекол та реакційних сумішей подано в табл. 1.

Таблиця 1. Молярне співвідношення компонентів шихти для фторидних стекол, \%

\begin{tabular}{|c|l|c|c|c|c|c|}
\hline \multirow{2}{*}{ 3разок } & \multirow{2}{*}{ Скло } & \multicolumn{5}{|c|}{ Компонент } \\
\cline { 3 - 7 } & & $\mathrm{ZrF}_{4}$ & $\mathrm{LaF}_{3}$ & $\mathrm{AlF}_{3}$ & $\mathrm{GaF}_{3}$ & $\mathrm{BaF}_{2}$ \\
\hline 1 & ZLAG & 67 & 27 & 1 & 5 & - \\
\hline 2 & ZBLA & 57 & 5 & 4 & - & 34 \\
\hline 3 & $\begin{array}{l}\text { 95 \% ZLAG + } \\
+5 \% \text { ZBLA }\end{array}$ & 66,5 & 25,9 & 1,15 & 4,75 & 1,7 \\
\hline
\end{tabular}

Наважки шихти після ретельного змішування та розтирання в агатовій ступці перенесені до платинового тигля зі спеціальною кришкою. 3 метою оптимізації процесу плавки скла експериментально було підібрано режими синтезу, що забезпечують завершення процесу за оптимальної тривалості в інертній атмосфері. Варка скла проводилася протягом 15 хв за температури $875^{\circ} \mathrm{C}$ для зразка 1 та $910{ }^{\circ} \mathrm{C}-$ для зразків 2 і 3. Після розплавлення шихти рідке скло переливалося у спеціальну бронзову форму для подальшого відпалу. Відпал проводився за температур 220 і $270{ }^{\circ} \mathrm{C}$ протягом 40 і 120 хв для зразків 1 та 2, 3 відповідно. Подальше охолодження проводилось повільно протягом кількох годин для повного зняття механічних напружень.

Стекла шліфували з використанням абразиву гранул $\mathrm{SiC}$ розміром 800 мкм. Для полірування використовували диск із тканиною, на яку наносили за допомогою спрею діамантову пудру з частинками розміром 6 мкм. Після полірування фторидні стекла переносили в ексикатор з нульовим парціальним тиском пари води.

Синтез оксофторидів РЗЕ проведено за методом твердофазової взаємодії компонентів при інертній атмосфері у запаяній платиновій трубці згідно з реакцією

$$
\mathrm{LnF}_{3}+\mathrm{Ln}_{2} \mathrm{O}_{3}=3 \mathrm{LnOF} .
$$

Люмінесцентні властивості оксофторидних матриць досліджено в системах на основі ітрію та гадолінію, оскільки вони мають широку область нестехіометричності, що відображається формулою $\mathrm{LnO}_{n-1} \mathrm{~F}_{n+2}$ при $n=4,5,6,7$.

Молярні співвідношення компонентів у реакційних сумішах наведені в табл. 2. 
Таблиця 2. Масовий склад компонентів оксофторидів ітрію, гадолінію з додаванням люмінофорів у мол. відсотках на 1 моль кінцевого продукту для стехіометричних сполук

\begin{tabular}{|c|c|c|c|c|c|c|c|c|c|}
\hline \multirow{3}{*}{$\begin{array}{c}\text { Спо- } \\
\text { лука }\end{array}$} & \multirow{2}{*}{$\begin{array}{c}\text { Вміст, } \\
\%\end{array}$} & \multicolumn{9}{|c|}{ ЕuOF } \\
\cline { 3 - 10 } & & $\mathrm{YF}_{3} / \mathrm{GdF}_{3}$ & $\mathrm{Y}_{2} \mathrm{O}_{3} / \mathrm{Gd}_{2} \mathrm{O}_{3}$ & $\mathrm{EuF}_{3}$ & $\mathrm{Eu}_{2} \mathrm{O}_{3}$ & $\mathrm{YF}_{3} / \mathrm{GdF}_{3}$ & $\mathrm{Y}_{2} \mathrm{O}_{3} / \mathrm{Gd}_{2} \mathrm{O}_{3}$ & $\mathrm{TbF}_{3}$ & $\mathrm{~Tb}_{2} \mathrm{O}_{3}$ \\
\hline \multirow{3}{*}{ YOF } & 5 & 0,3629 & 0,5617 & 0,0281 & 0,0473 & 0,3618 & 0,5599 & 0,0291 & 0,0492 \\
\cline { 2 - 11 } & 10 & 0,3333 & 0,5158 & 0,0562 & 0,0947 & 0,3311 & 0,5124 & 0,0581 & 0,0984 \\
\cline { 2 - 10 } & 15 & 0,3037 & 0,47 & 0,0843 & 0,142 & 0,3004 & 0,4648 & 0,0871 & 0,1477 \\
\hline \multirow{3}{*}{ GdOF } & 5 & 0,3534 & 0,598 & 0,0181 & 0,0305 & 0,3528 & 0,5968 & 0,0187 & 0,0317 \\
\cline { 2 - 10 } & 10 & 0,3353 & 0,5674 & 0,0362 & 0,061 & 0,334 & 0,5651 & 0,0374 & 0,0634 \\
\cline { 2 - 11 } & 15 & 0,3173 & 0,5368 & 0,0543 & 0,0915 & 0,3153 & 0,5334 & 0,0562 & 0,0951 \\
\hline
\end{tabular}

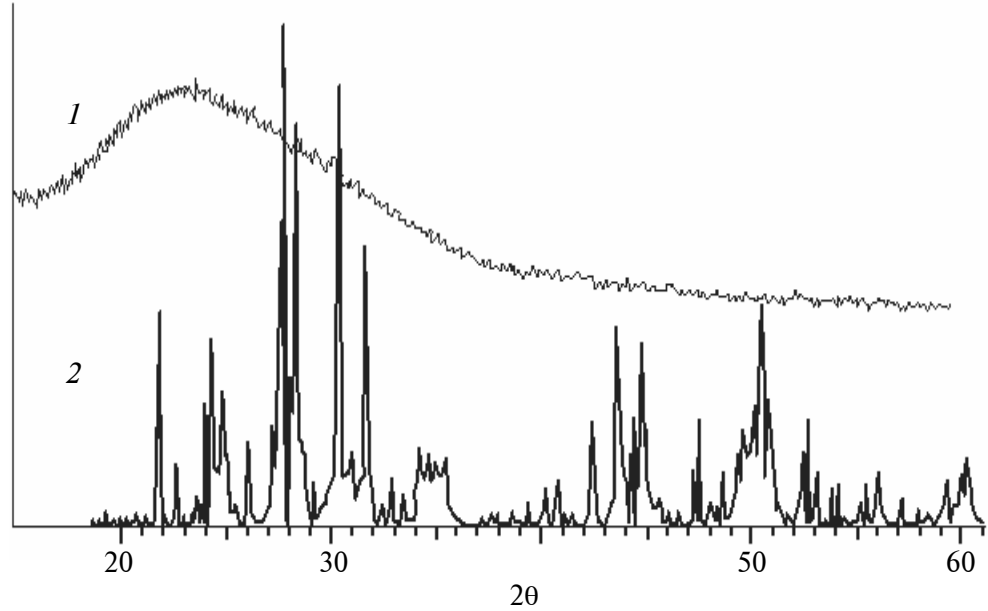

Рис. 1. Дифрактограма вихідного фторидного скла (1) і скла $95 \%$ ZLAG + $+5 \%$ ZBLA після перебування протягом кількох днів на повітрі (2)
Термічні дослідження проводилися за допомогою аналізатора SDT Q600 в атмосфері аргону з параметрами: інтервал температур для скла $20-540^{\circ} \mathrm{C}$, для оксофторидів - 20$1000{ }^{\circ} \mathrm{C}$, швидкість нагріву $-5 \mathrm{i}$ $3{ }^{\circ} \mathrm{C} /$ хв для скла та оксофторидів відповідно, швидкість охолодження $10{ }^{\circ} \mathrm{C} / \mathrm{Xв}$.

Методом диференціального термічного аналізу (ДТА) досліджено три типи стекол: ZBLA, ZLAG, $95 \%$ ZLAG $+5 \%$ ZBLA. На рис. 2 зображені термограми цих трьох матриць: чітко проявляються області кристалізації та температури склування.

Як видно з порівняльної діаграми, для скла ZBLA спостерігається ряд піків кристалізації, що свідчить про поступову кристалізацію трьох різних фаз у матриці скла. Натомість у двох інших фторидних стеклах спостерігається лише один ефект. Отримані результати свідчать: скло ZLAG є більш тугоплавким, інтервал між температурою склування та кристалізацією для нього

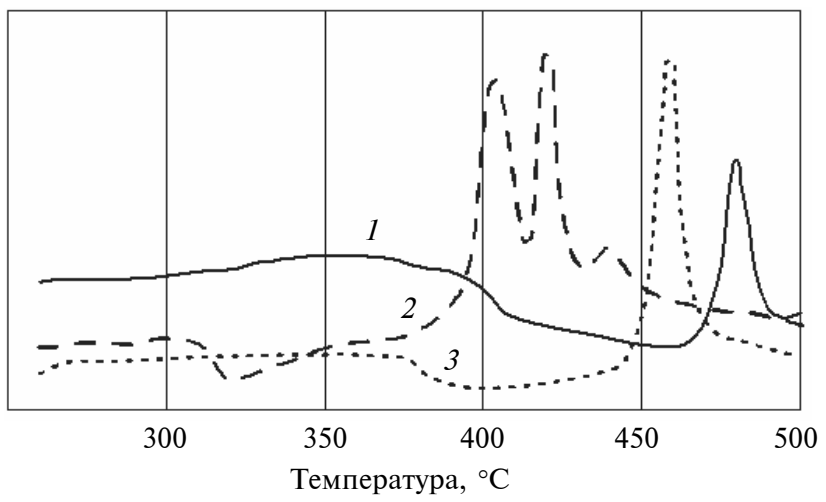

Рис. 2. Порівняльна діаграма ДТА синтезованих стекол різного складу: 1 - ZLAG; 2 - ZBLA; 3 - $95 \%$ ZLAG + $+5 \%$ ZBLA результату призводить додавання до складу матриці люмінофору (>10\%). 
менший, що пояснює низьку стабільність зазначеної матриці та проблеми при розробці методики iї синтезу.

Введення до вихідної реакційної суміші невеликої кількості скла ZBLA призводить до значних змін: змінюються його термічні характеристики та виникає можливість отримання масивних зразків однорідного скла. Легувальні домішки люмінофорів мало впливають на термічну поведінку усіх матриць (варіювання становить близько $2^{\circ} \mathrm{C}$ ), знижуючи температуру склування і температуру кристалізації скла на основі ZLAG та підвищуючи температуру склування ZBLA.

За допомогою термічного аналізу досліджено особливості взаємодії між оксофторидами ітрію та гадолінію: термічні ефекти для усіх сумішей спостерігаються в широкому температурному інтервалі, що свідчить про складну взаємодію між вихідними реагентами.

Взаємодія між $\mathrm{YF}_{3} \mathrm{i}_{2} \mathrm{O}_{3}$ за результатами ДТА починалась за температури вище $400^{\circ} \mathrm{C}$ (рис. 3). Процес супроводжувався екзотермічним ефектом в інтервалі температур 400$590{ }^{\circ} \mathrm{C}$ з максимумом при $530^{\circ} \mathrm{C}$. Для системи $\mathrm{GdF}_{3}: \mathrm{Gd}_{2} \mathrm{O}_{3}$ відзначено слабкий ендотермічний ефект в області $693-775^{\circ} \mathrm{C}$ (рис. 3). Елементний склад зразка, відібраного після завершення ендоефекту, відповідав формулі GdOF. Синтезовані оксофториди при повторних нагріваннях залишались стабільними, за даними ДТА, та не показували жодних змін, що підтверджує високий вихід при синтезі й термічну стійкість кінцевого продукту.

Для дослідження люмінесцентних властивостей фторидного скла у видимій області випромінювання використовували спектрофлуориметр Edimbourg FLSP920.

Довжина хвилі збудження становила 255 нм. Для дослідження вибрано матрицю загального

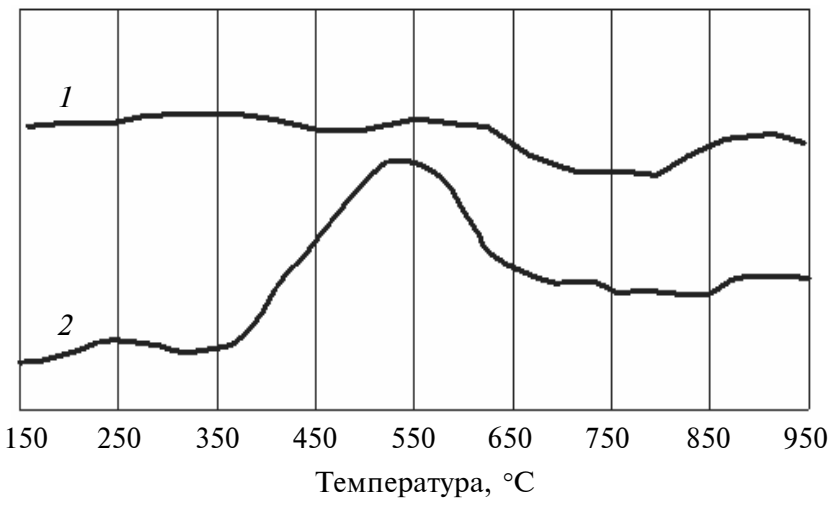

Рис. 3. ДТА реакційних сумішей: $1-\mathrm{GdF}_{3}: \mathrm{Gd}_{2} \mathrm{O}_{3} ; 2-\mathrm{YF}_{3}: \mathrm{Y}_{2} \mathrm{O}_{3}$ складу $95 \%$ ZLAG + $5 \%$ ZBLA із вмістом легувальних домішок фторидів ітрію та гадолінію відповідно у кількості 5, 10 та 15 мол. \%. 3 рис. 4 видно, що зі збільшенням вмісту люмінофору спостерігається підвищення інтенсивності піків люмінесценції, які відповідають електронним переходам ${ }^{5} D \rightarrow{ }^{7} F$.
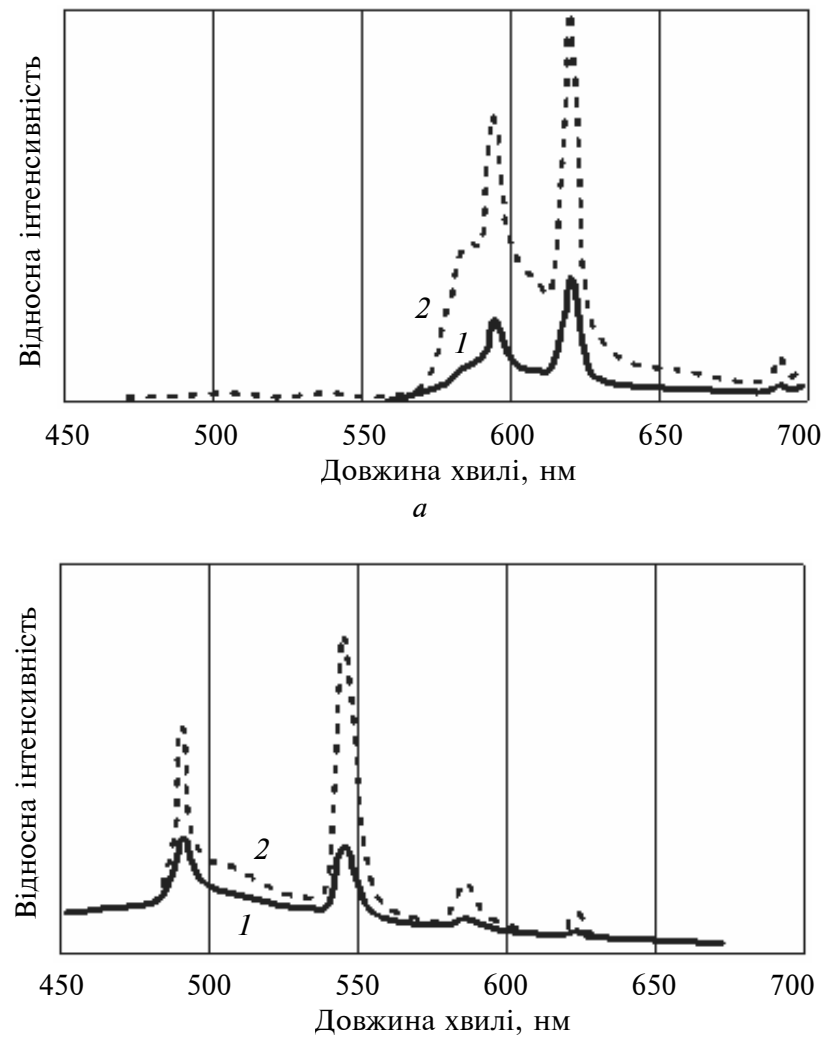

$\sigma$

Рис. 4. Спектр люмінесценції фторидних стекол: $a-$ скло, леговане $\mathrm{EuF}_{3} ; \sigma$ - скло, леговане $\mathrm{TbF}_{3} ; 1-5$ мол. \% легувальної домішки, 2 - 10 мол. \% легувальної домішки

Для легованого європієм скла ефект спостерігається у діапазоні 580-630 нм. Оскільки скло є аморфним утворенням, то області спостереження ефекту є протяжними, малоінтенсивними та не мають чіткого екстремуму.

При легуванні скла фторидом тербію спостерігається схожа картина: зі збільшенням вмісту тербію інтенсивність люмінесценції зростає. Піки, як і для попереднього зразка, залишаються досить широкими та не мають чіткої форми. Максимальна інтенсивність випромінювання спостерігається при 545 нм.

При використанні ультрафіолетового випромінювання можна відзначити, що фторидні стекла, леговані європієм, мають більшу інтенсивність світіння. Це може бути спричинено 


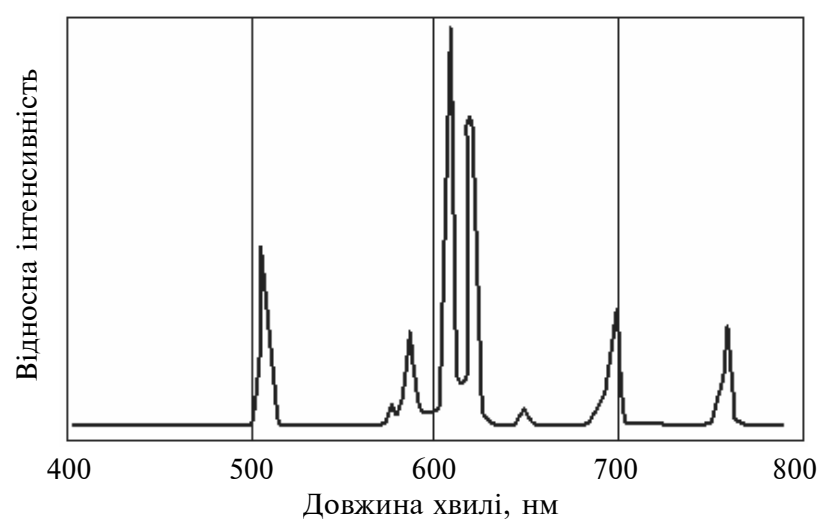

Рис. 5. Спектр люмінесценції GdOF +10 мол. \% ЕuOF

енергетичним зміщенням піків у вузькому діапазоні спектра випромінювання. Для тербію піки розміщені в більшому інтервалі довжин хвиль.

Для оксофторидів ітрію та гадолінію спостерігається тенденція зростання квантового виходу до концентрації люмінофорів 10 мол. \%, при подальшому збільшенні вмісту сполук європію чи тербію у фторидній матриці спостерігається зниження інтенсивності люмінесценції.

3 рис. 5 видно, що основна частина випромінювання для матеріалів, легованих європієм, спостерігається в області спектра 500-700 нм. При цьому варто відзначити, шо оксофториди на основі гадолінію мають дещо більшу яскравість.

Інтенсивність світіння оксофторидів значно більша порівняно зі стеклами. Піки люмінесценції зазвичай мають симетричну форму, що вказує на високий ступінь кристалізації. Завдяки цьому яскравість отриманих пудр може спостерігатися навіть при помірному денному світлі.

Спектр випромінювання тербію в області 480-700 нм (рис. 6) для оксофторидів має складний характер, що можна пояснити розщепленням енергетичних рівнів ${ }^{7} F_{j}$. Основна частина ж випромінювання міститься в зоні довжин хвиль, що відповідають зеленому світлу.

\section{Висновки}

У роботі досліджено можливість створення люмінесцентних матеріалів на основі фторидного скла складу $95 \%$ ZLAG $+5 \%$ ZBLA і оксофторидів РЗЕ та ітрію на прикладі сполук ітрію та гадолінію. При синтезі скломатеріалів у ролі люмінофорів використано сполуки євро-

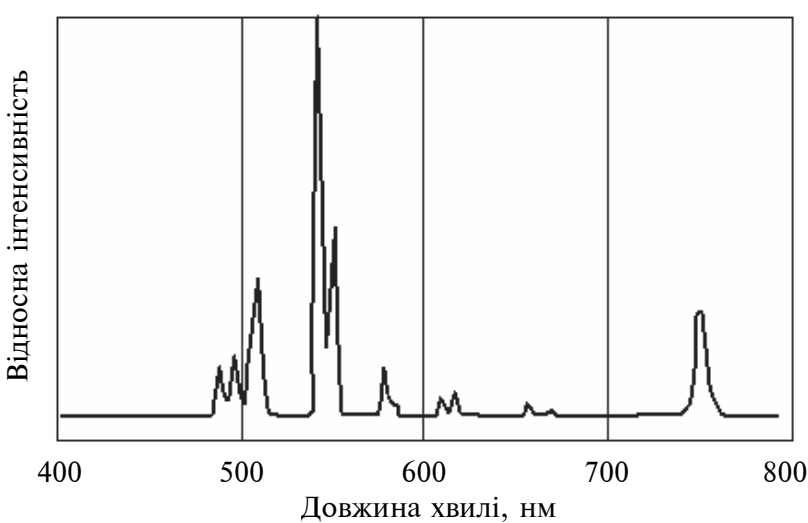

Рис. 6. Спектр люмінесценції GdOF + 10 мол. \% TbOF

пію та тербію, які при збудженні випромінюють світло у видимій частині спектра.

За результатами досліджень можна зробити висновок, що синтезовані фторидні стекла можуть розглядатись як перспективні матеріали для оптичних підсилювачів та лазерів, для яких, крім фізичних особливостей матеріалу, однією з основних вимог є можливість надання необхідної геометричної форми готовому виробу. Маючи низькі показники затухання та широке вікно прозорості, синтезовані стекла все ж є хімічно нестійкими до агресивних середовищ, тому мають функціонувати в інертній атмосфері у герметично ізольованих зонах або 3 нанесенням шару захисного покриття.

Подальші дослідження варто спрямувати на зведення до мінімуму двох основних вад синтезованих стекол: підвищеної кристалізаційної здатності та низької хімічної стійкості. Такими відповідними технологічними заходами може бути пошук нових специфічних інгредієнтів скляної матриці, так званих інгібіторів кристалізації, а також модифікування поверхневого шару готових виробів 3 метою усунення пагубного впливу атмосферного повітря.

$$
* * *
$$

Автори глибоко вдячні викладачам Університету Ле-Ман, м. Ле-Ман, Франція, професору Крістофу Лєжену та доктору Бельто Дьйодонну, а також професору Бріжіт Булард, інженеру CEA відділу LITEN/DTBH/SCSH/LPH, м. Гренобль, Франція, за допомогу в синтезі люмінесцентних матеріалів і дослідженні отриманих зразків.

\section{Список літератури}

1. Никоров Н.В., Сидоров А.И. Материалы и технологии волоконной оптики: специальные оптические волокна. - СПб: ITMO, 2009. - C. 131-136. 
2. Термическое разложение природных фторкарбонатов и фторидов редкоземельных элементов / И.Т. Александрова, Г.А. Сидоренко, В.И. Николаев и др. // Труды Всесоюзного симпозиума по химии неорганических фторидов. Одесса, 1972. - С. 118-119.

3. Luminescent properties of eu-doped lanthanum oxyfluoride sol-gel thin films / L. Armelao, G. Bottaro, L. Bovo et al. // J. Phys. Chem. C. - 2009. - 113. - P. 14429-14434.

4. Josse E., Fonteneau G., Lucas J. Low-phonon waveguides made by F-/Cl- exchange on fluoride glasses // Mater. Res. Bull. 1997. - 32, № 9. - P. 1139-1146.

\section{References}

1. N.V. Nikorov and A.I. Sidorov, Materials and Technologies of Fiber Optics: the Special Optical Fibres. St. Petersburg, Russia: ITMO, 2009, pp. 131-136 (in Russian).

2. I.T. Aleksandrova et al., "Thermal decomposition of natural fluorine of carbonates and fluoriets of rare-earth elements", in Proc. All-Union Symposium Works on the Chemistry of Inorganic Fluorides, Odessa, Ukraine, 1972, pp. 118-119 (in Russian).

3. L. Armelao et al., "Luminescent properties of eu-doped lanthanum oxyfluoride sol-gel thin films", J. Phys. Chem. C., vol. 113, pp. 14429-14434, 2009.

4. E. Josse et al., "Low-phonon waveguides made by $\mathrm{F}^{-} / \mathrm{Cl}^{-}$exchange on fluoride glasses", Mater. Res. Bull., vol. 32, no. 9, pp. 1139-1146, 1997.

\section{С.В. Пилипко, Л.М. Спасьонова, М.М. Племянніков}

\section{СИНТЕЗ ЛЮМІНЕСЦЕНТНИХ МАТЕРІАЛІВ НА ОСНОВІ РІДКІСНОЗЕМЕЛЬНИХ ОКСОФТОРИДІВ}

Проблематика. Розробка нових матеріалів для систем відображення та реєстрації оптичних сигналів, які можуть працювати в діапазоні інфрачервоного випромінювання, залишається актуальною. Галузь оптики зіткнулася з проблемою, коли відомі системи на основі силікатного скла не забезпечують необхідної ширини зони прозорості, а матеріали на основі фторидів металів мають низьку хімічну стійкість.

Мета дослідження. Розробка методології, спрямованої на синтез та дослідження властивостей фторидних стекол і оксофторидів рідкісноземельних елементів (РЗЕ) та ітрію.

Методика реалізації. Застосовано комплексний підхід до синтезу та досліджень із використанням термічних, рентгенівських, люмінесцентних та інших методів. Як вихідні речовини використовувалися комерційні сполуки $\mathrm{ZrF}_{4} ; \mathrm{LaF}_{3} ; \mathrm{AlF}_{3} ; \mathrm{GaF}_{3} ; \mathrm{BaF}_{2}$; $\mathrm{YF}_{3} ; \mathrm{Y}_{2} \mathrm{O}_{3} ; \mathrm{EuF}_{3} ; \mathrm{Eu}_{2} \mathrm{O}_{3} ; \mathrm{GdF}_{3} ; \mathrm{Gd}_{2} \mathrm{O}_{3} ; \mathrm{TbF}_{3} ; \mathrm{Tb}_{2} \mathrm{O}_{3}$.

Результати дослідження. Досліджено можливість створення люмінесцентних матеріалів на основі фторидного скла складу 95 \% ZLAG + 5 \% ZBLA та оксофторидів PЗЕ. При синтезі цих матеріалів як люмінофори було використано сполуки європію і тербію, які випромінюють світло у видимій частині спектра.

Висновки. Синтезовані фторидні стекла можуть бути використані як перспективні матеріали для оптичних підсилювачів та лазерів. Оксофториди, маючи гарні показники виходу фотолюмінесценції та фрізико-хімічну інертність до агресивних середовищ, можуть стати перспективними матеріалами для виготовлення люмінесцентних матеріалів для широкого використання.

Ключові слова: люмінесцентні матеріали; фторидне скло; оксофториди; рідкісноземельні елементи.

\section{С.В. Пилипко, Л.М. Спасёнова, Н.Н. Племянников}

\section{СИНТЕЗ ЛЮМИНЕСЦЕНТНЫХ МАТЕРИАЛОВ НА ОСНОВЕ РЕДКОЗЕМЕЛЬНЫХ ОКСОФТОРИДОВ}

Проблематика. Разработка новых материалов для систем отражения и регистрации оптических сигналов, которые могут работать в диапазоне инфракрасного излучения, остается актуальной. Отрасль оптики столкнулась с проблемой, когда известные системы на основе силикатного стекла не обеспечивают необходимую ширину зоны прозрачности, а материалы на основе фторидов металлов имеют низкую химическую стойкость.

Цель исследования. Разработка методологии, направленной на синтез и исследование свойств стекол фрторидов и оксофрторидов редкоземельных элементов (РЗЭ) и иттрия.

Методика реализации. Применен комплексный подход относительно синтеза и исследований с использованием термических, рентгеновских, люминесцентных и других методов. В качестве исходных веществ использовались коммерческие соединения $\mathrm{ZrF}_{4} ; \mathrm{LaF}_{3} ; \mathrm{AlF}_{3} ; \mathrm{GaF}_{3} ; \mathrm{BaF}_{2} ; \mathrm{YF}_{3} ; \mathrm{Y}_{2} \mathrm{O}_{3} ; \mathrm{EuF}_{3} ; \mathrm{Eu}_{2} \mathrm{O}_{3} ; \mathrm{GdF}_{3} ; \mathrm{Gd}_{2} \mathrm{O}_{3} ; \mathrm{TbF}_{3} ; \mathrm{Tb}_{2} \mathrm{O}_{3}$.

Результаты исследований. Исследована возможность создания люминесцентных материалов на основе фрторидного стекла состава 95 \% ZLAG + 5 \% ZBLA и оксофторидов РЗЭ. При синтезе данных материалов в роли люминофоров были использованы соединения европия и тербия, которые излучают свет в видимой части спектра.

Выводы. Синтезированные стекла фрторидов могут быть использованы в качестве перспективных материалов для оптических усилителей и лазеров. Оксофториды, имея хорошие показатели выхода фотолюминесценции и фризико-химическую инертность к агрессивным средам, могут стать перспективными материалами для изготовления люминесцентных материалов для широкого использования.

Ключевые слова: люминесцентные материалы; фторидное стекло; оксофториды; редкоземельные элементы.

Рекомендована Радою

хіміко-технологічного факультету

НТУУ “КПІ"
Надійшла до редакції

2 лютого 2016 року 
